\title{
Factors Influencing Neck Pain among Computer Users
}

\section{Dr Md Harun-Or-Rashid1*, Dr Abul Hasnat Mohiuddin², Dr Md Arafat Hossin $^{3}$, Dr Aminul Islam ${ }^{4}$ Dr Md Ashraful Alam ${ }^{5}$ and S M Imran Shoaib ${ }^{6}$}

${ }^{1}$ Consultant (Physiotherapy), New Life Trauma Centre, Rampura, Dhaka-1216.

Bangladesh Email: hawlader172@gmail.com

${ }^{2}$ Assistant Professor and Head of Physiotherapy Department, Dhaka College of

Medical and Technology, Mohammadpur, Dhaka. Bangladesh \& Consultant

(Physiotherapy), Islami Bank Central Hospital Kakrail, Dhaka-1000, Bangladesh

Email: hasnat.bpt@gmail.com

${ }^{3}$ Head of Physiotherapy Department, TMSS Medical College and Hospital, Bogura,

Bangladesh Email: arafatr_1f@yahoo.com

${ }^{4}$ Consultant and Head of Physiotherapy Department, Super Medical Hospital Private

Ltd, Savar, Dhaka-1340, Bangladesh Email: aminul_physio@yahoo.com

${ }^{5}$ Consultant (Physiotherapy), Jatio Protibondhi Unnayan Foundation, Ministry of

social Welfare, Govt. of Bangladesh Email: mdashraful-2017452018@dps.du.ac.bd

${ }^{6}$ Technical Director, STEP Rehabilitation Centre, Shymoli, Dhaka, Bangladesh.

Email: orthotistcrp@yahoo.com

*Corresponding Author: Md Harun-Or-Rashid, Consultant (Physiotherapy), New

Life Trauma Centre, Rampura, Dhaka, Bangladesh.
Received: May 23, 2021

Published: June 03, 2021

(C) All rights are reserved by Dr Md Harun

-Or-Rashid., et al.

\begin{abstract}
Introduction: Neck pain is a common problem for people who spend a great deal of time using computers. Computer based customer service work or call centre work is one of the most rapidly growing occupations in the world. Musculoskeletal disorders of the upper extremities and neck are the most common occupational health problem associated with this type of work. It has been stated that neck pain is the common occupational health problem (New guidance on using computers and preventing, 2003).

Methodology: Cross sectional research in this study with 75 participants were collected from new life trauma centre at Rampura, Dhaka, Bangladesh and captured in Excel, using an SPSS 24.0 version programs.

Results: The total participant of the study was 75. The age group was participant from $21-54$ years. Mean 33 and (SD \pm 8.599 ). Among the 75 participants $92 \%(n=69)$ were Muslim and 5.3\% $(n=4)$ were Hindu in religion and Christian were 2.7\% $(n=2)$. Sec
\end{abstract}


ondary school certificate $8 \%(n=6)$, higher secondary school certificate $10.66 \%(n=8)$, Bachelor degree $44 \%(n=33)$. And master degree $37.3 \%(n=28)$. In this study total participants were 75 were affected from non Diabetics mellitus $76 \%(n=57)$ and they were $24 \%(n=18)$ affected Diabetics mellitus. Study found that majority cases $44 \%(n=33)$ participants were overweight BMI whereas $13.3 \%(\mathrm{n}=10)$ respondents were class I obesity and $1.3 \%$ underweight also be $1 \%$ and $41.3 \%(n=31)$. The highest participant were 32 in range of 25 degree with worked hours 9 so that more significant of the study. So result was significant. Relationship between neck disability and working time the study was found in reading of NDI minimum scoring 1-2 were 65 participants and result was significant.

Conclusion: Now a day's various types of computer related musculoskeletal disorders are increasing in Bangladesh due to increasing use of computer tremendously in all sectors to improve the quality of health care system as well as the efficiency of health workers and other workers

Keywords: Body Mass Index; Minimal Detectable Change; Neck Disability Index; Range of Motion; Visual Analog Scale; Work Related Neck Pain

\section{Abbreviations}

BMRC: Bangladesh Medical Research Council; MCID: Minimal Clinically Important Deference; MDC: Minimal Detectable Change; NDI: Neck Disability Index; ROM: Range of Motion; VAS: Visual Analog Scale; WRNP: Work Related Neck Pain

\section{Introduction}

Neck pain is a common problem for people who spend a great deal of time using computers. Neck pain is the pain experienced anywhere from the base of the skull at ear level to the upper part of the back or shoulder. Computer based customer service work or call centre work is one of the most rapidly growing occupations in the world [1]. Musculoskeletal disorders of the upper extremities and neck are the most common occupational health problem associated with this type of work [2]. Nowadays computers have become a vital tool to keep pace with time and progress. A variety of sectors including banks, government offices, private entities, autonomous institutions etc. have computerized their data systems for smooth and faster flow of information [1]. Rapid technological developments, especially in the use of electronic data, have affected workers. Electronic data are mainly displayed on visual display screen. Improper body posture and long hours in front of these instruments can result in many health hazards such as neck pain [3]. It has been stated that neck pain is the common occupational health problem (New guidance on using computers and preventing, 2003) [4]. Statistics show that around $10-15 \%$ of the popula- tion has neck pain at any given time (National health and medical research council, 2000) [5]. Normal neck function underpins successful performance of activities of daily living. In the general population, neck pain and dysfunction are common, affecting up to $67 \%$ of the general population at some time during their life [6]. The one year prevalence of neck pain has been reported normal neck function as $32 \%$ in a population of Hong Kong Chinese [7]. Many studies have investigated the relationship between neck pain and working conditions. Office workers are a specific population at high risk of developing neck pain, with one year prevalence rates much higher than in the general population [8]. One year prevalence of neck pain in office workers at a Hong Kong university was found to be $59 \%$ (8) and 63\% in a Swedish study of medical secretaries [9]. The epidemiology of neck pain is important for several reasons. More knowledge about the size and extent of this problem would facilitate accurate predictions of the need for medical services and direct resources. Moreover, the prevalence of neck pain in the general population is essential for determining the relation between trauma and occupation [9].

Several possible path physiological mechanisms of neck pain disorders have been proposed in the literature. According to Visser and Van Dieën [10], it is unlikely that a single comprehensive patho physiological mechanism exists that is responsible for tissue damage.

Work related neck disorders are common problems in office workers, especially among those who are intensive computer users 
[11]. The worldwide trend is for people to use computers for longer periods daily, due to increased computer-based tasks at work as well as during leisure activities. Introduction of the computer into the workplace has changed in work organization, and a different use of worker physical and mental potential. It is generally agreed that the etiology of work related neck disorders is multidimensional which is associated with, and influenced by, a complex array of individual, physical and psychosocial factors. Among these various risk factors, work-related psychosocial factors appear to play a major role.

For people who spend a great deal of time using computers, WRMSDs of the neck are a common problem. The term Work-Related Neck Pain (WRNP) is employed in this article; "computer" refers to desktop and laptop or notebook personal computers, video display units, and video display screens, to include the use of keyboards and pointing devices [12].

Epidemiological evidence appropriate to WRNP associated with computer used; individual, social, behavioral, and psychological issues relevant to WRNP are presented; and preventive and health policy strategies that may be considered to assist in controlling the problem of WRNP are suggested [13]. The available epidemiological evidence suggests that hand; arm, shoulder and neck symptoms are associated with the duration of computer use and increase steadily with each hour of computer use per day [14]. A study showed that the one-year prevalence of complains of arm, neck and shoulder (CANS) was $56.9 \%$, commonest region of complaint was forearm/hand (42.6\%), followed by neck (36.7\%) and shoulder/ $\operatorname{arm}(32.0 \%)$ [15].

\section{Justification of the Study}

Although some studies have dealt with neck pain among computer user in other countries, the exact nature and prevalence of this important health problem has not been studied before in Bangladesh. This study was formulated to fill the gap of knowledge in this area. The aims of the study were to assess the pattern of neck among computer user and to identify the impact of demographic, occupational, psychological and social factors on them. Beside this it will help to established ergonomic guidelines for space, equipment, furniture and environmental conditions which are mandatory in the design of working place of the computer user. This study will also help to discover the lacking area of a computer user, especially about their posture before doing any activities. Beside this it will help to professional development which is mandatory for cur- rent situation. The identification of risk factor of neck pain can help act as preventive method of neck pain and give proper education about their bad posture. And it will help to discover the role and importance of physiotherapy in every sector of Bangladesh. World is now very much depend on computer. Nowadays Bangladesh is in the revolution toward Digital Bangladesh which indicates increase use of information technology in every aspect. Therefore, computer will be a common work tool in almost every workstation in perspective of Bangladesh. With an increase in the intensity, frequency and popularity of computer use inside and outside at home, the incidence of WMSDs has been increased. However, there are only few attempts to inquire this site of health service. From the study computer users will be able to identify the musculoskeletal problem related to their work that can influence their activities. They may provide proper recommendation for every problem which will be helpful for them. This study will also help to discover the lacking area of computer users about their posture before doing any activities. From the study the researcher can identify the most vulnerable area the body where the prevalence of work related musculoskeletal disorders is at higher rate. Thus, the computer users can be aware about the poor posture of that particular area. It has been shown in a study that technical computer operators are highly affected.

\section{Materials and Methods}

The purpose of the study was to find out the prevalence of neck pain among the computer users. The cross sectional study was conducted to find out the objectives. The study area was the new life trauma centre at Rampura, Dhaka. In this study, sample populations were selected from the participant of different occupation who was suffering from neck pain report at new life trauma centre, Rampura, Dhaka. There are a lot of computer worker in Bangladesh, from this population it was selected 75 samples, according to the inclusion and exclusion criteria. Because it was not possible to study the total population within the time of this study. Data collection instruments were used VAS (Visual Analog Scale) and NDI (Neck Disability Index) with some objective questions which were measured by examiner and each question was formulated to find out the change of pain with each activity. The data analysis was performed in SPSS version 24.

\section{Results and Discussion}

This cross-sectional study was the socio-demographic information along with Work Related neck pain was taken from 75 participants who work as a professional computer user by the researcher. 
The data were collected from $1^{\text {st }}$ January to $30^{\text {th }}$ June 2019 , by selecting the participants purposively using semi-structured questionnaire.

\section{Age of the participants}

The total participant of the study was 75 . The age group was participant from 21-54 years. Mean 33 and (SD \pm 8.599 ). Figure 1 shows the distribution of age of the participants in bar.

Age distribution of the participants

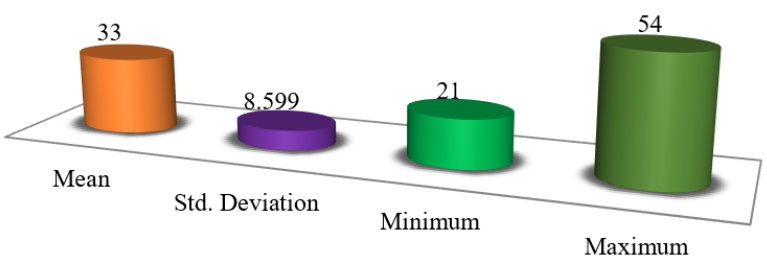

Figure 1: Age distribution of the participants.

\section{Patient rated pain in general (VAS)}

Study found that majority cases $48 \%(n=36)$ participants were scoring VAS 6 whereas 28\% $(n=21)$ respondents were VAS scoring $7,16 \%(n=12)$ participants were VAS scoring $8,5.3 \%(n=4)$ participants were VAS scoring 5 and $2.7 \%(n=2)$ participants were VAS scoring 9 in figure 2 showed.

Distribution of the respondents by Visual analogue Scale.

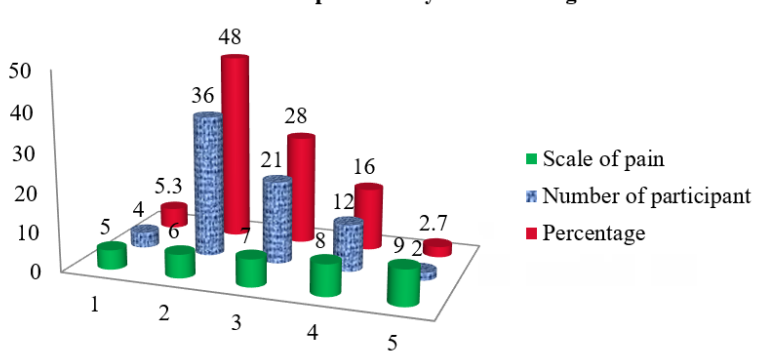

Figure 2: Distribution of the respondents by visual analogue Scale.

\section{Neck disability index}

Study found that pain intensity of the neck here statistical analysis range 3 and minimum scoring 1 and maximum scoring 4 .
Personal care of the NDI analysis range 3 and minimum scoring 1 and maximum scoring 4 . Weight carrying of the respondent of NDI analysis range 3 and minimum scoring 1 and maximum scoring 4. Reading ability of the respondent of NDI analysis range 3 and minimum scoring 1 and maximum scoring 4. Headache of the respondent of NDI analysis range 1 and minimum scoring 1 and maximum scoring 2 . Concentration of the respondent of NDI analysis range 2 and minimum scoring 1 and maximum scoring 2 . Work of the respondent of NDI analysis range 2 and minimum scoring 1 and maximum scoring 3. Driving of the respondent of NDI analysis range 2 and minimum scoring 1 and maximum scoring 3. Sleeping of the respondent of NDI analysis range 3 and minimum scoring 1 and maximum scoring 4 . Recreation of the respondent of NDI analysis range 3 and minimum scoring 1 and maximum scoring 4 in figure 3 showed.

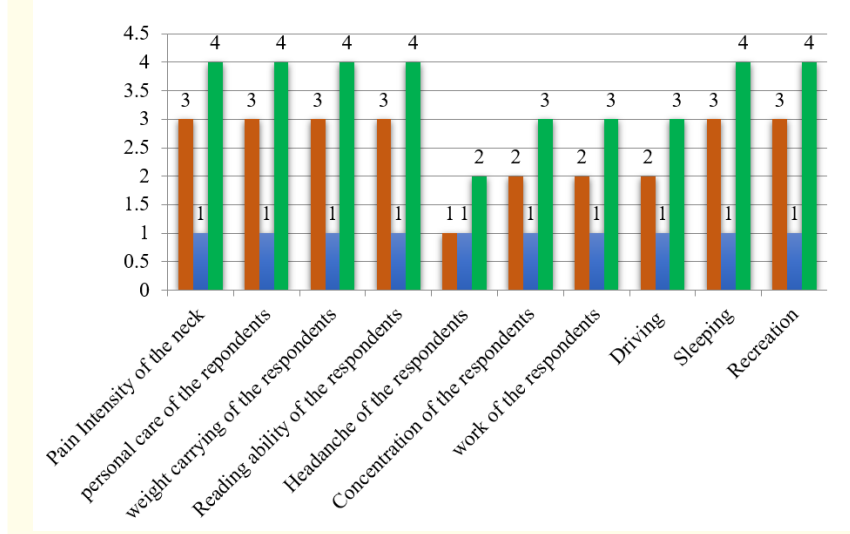

Figure 3: Neck disability index analysis.

\section{Educational status of participants}

Their educational level was below secondary school certificate $4 \%(n=3)$, secondary school certificate $4 \%(n=3)$, higher secondary school certificate 10.7\% ( $n=8)$, Bachelor degree 44\% ( $n=33)$. And master degree $37.3 \%(n=28)$. Table 1 showed the educational status of the participants.

\section{Body mass index Information of the Participant}

Study found that majority cases $44 \%(n=33)$ participants were overweight BMI whereas 13.3\% $(n=10)$ respondents were class I obesity and $1.3 \%$ underweight also be $1 \%$ and $41.3 \%(n=31)$ normal weight in table 2 showed. 


\begin{tabular}{|l|c|c|}
\hline \multicolumn{1}{|c|}{ Educational status } & Number(n) & Percent (\%) \\
\hline $\begin{array}{l}\text { Below secondary school } \\
\text { certificate }\end{array}$ & 3 & 4 \\
\hline Secondary school certificate & 3 & 4 \\
\hline $\begin{array}{l}\text { Higher secondary school } \\
\text { certificate }\end{array}$ & 8 & 10.7 \\
\hline Bachelor degree & 33 & 44 \\
\hline Master degree & 28 & 37.3 \\
\hline
\end{tabular}

Table 1: Educational status of the participants.

\begin{tabular}{|l|c|c|}
\hline Valid & Frequency & Percentage \\
\hline 1 & 1 & $1.3 \%$ \\
\hline 2 & 31 & $41.3 \%$ \\
\hline 3 & 33 & $44.0 \%$ \\
\hline 4 & 10 & $13.3 \%$ \\
\hline Total & 75 & $100 \%$ \\
\hline
\end{tabular}

Table 2: Body mass index of the respondents.

\section{Muscle strength analysis (OXFORD scale)}

Study found that flexor strength of the neck here statistical analysis scoring 1. Extensor strength of the neck range analysis scoring 1. Rotation strength of the analysis scoring 3. Side flexion of the neck range analysis scoring 1 in figure 4 showed.

\section{Muscle grading (OXFORD Scale)}

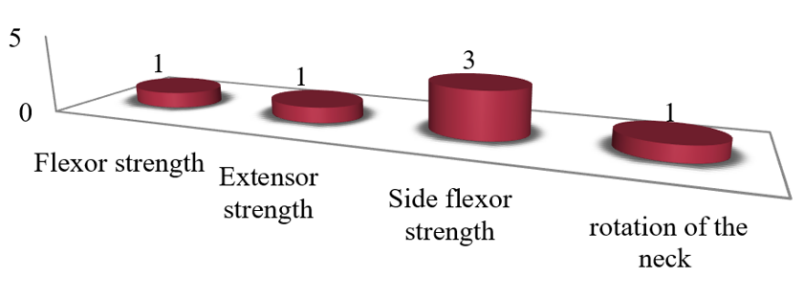

- Muscle grading (OXFORD Scale)

Figure 4: Muscle strength analysis (OXFORD scale).

\section{Diabetes mellitus Information of the Participant}

In this study total participants were 75 and among them 75 participants were affected from non Diabetics mellitus 76\% ( $n=57)$ and they were $24 \%(n=18)$ affected Diabetics mellitus. Figure 5 showed.

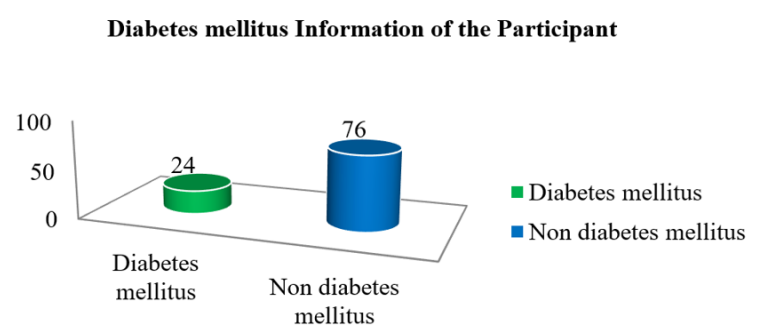

Figure 5: Diabetes mellitus Information of the Participant.

\section{Range of motion analysis}

Study found that flexion of the neck range 32, Extension of the neck range 40 degree, Side flexion of the neck range average 25 degree, right rotation of the neck range 52 degree and left rotation of the neck range 52 in figure 6 showed.

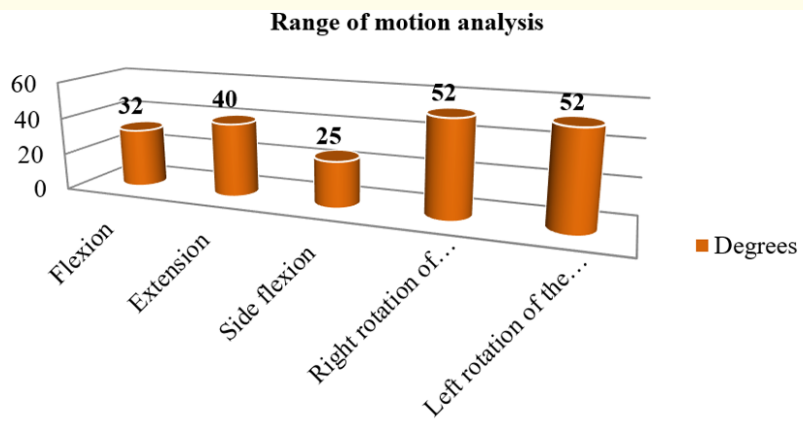

Figure 6: Range of motion analysis.

Respondents with working time Vs range of motion

The 75 participants those were 17 participants was inner range (18 - 24 degree) with worked hours average 6, were in the 32 participants in middle range (25 - 32 degree) with worked hours average 9 and 26 participants were outer range (34-50 degree) with worked hours average 9.

This observed Chi-square value was 98.168 and P-value 0.821. So, there was no significant association between hours of work and influence on range of motion of cervical spine. Therefore, employee who works for 1 - 3 hours (group-1), 4 - 6 hours (group-2) and 7 - 9 hours (group-3) did not differ drastically in relation to cervical spine range of motion. 


\begin{tabular}{|l|c|c|c|c|}
\hline Range of motion (flexion) \\
\hline Working time & $\begin{array}{c}\text { Inner range (18-24) } \\
\text { degree }\end{array}$ & $\begin{array}{c}\text { Middle range (25-32) } \\
\text { degree }\end{array}$ & $\begin{array}{c}\text { Outer range (34-50) } \\
\text { degree }\end{array}$ & Total \\
\hline Group 1 (1-3) hours & 0 & 3 & 2 & 5 \\
\hline Group-2 (4-6) hours & 12 & 12 & 10 & 34 \\
\hline Group-3 (7-9) hours & 5 & 17 & 14 & 36 \\
\hline Total & 17 & 32 & 26 & 75 \\
\hline
\end{tabular}

Table 3: Respondents with working time Vs range of motion (flexion).

\begin{tabular}{|l|c|c|}
\hline \multirow{2}{*}{$\begin{array}{l}\text { Working time and range of } \\
\text { motion }\end{array}$} & Chi-Square & P-value \\
\cline { 2 - 3 } & 98.168 & 0.821 \\
\hline
\end{tabular}

Table 4: Relationship between working time and range of motion.

Respondents with participant age vs visual analog scale

\begin{tabular}{|l|c|c|c|c|}
\hline Age group & VAS & VAS & VAS & Total \\
\hline $23-33$ & $\mathbf{5 - 6}$ & $\mathbf{7 - 8}$ & $\mathbf{9}$ & \\
\hline $34-44$ & 17 & 7 & 0 & 22 \\
\hline $45-56$ & 8 & 12 & 2 & 33 \\
\hline Total & 40 & 33 & 2 & 75 \\
\hline
\end{tabular}

Table 5: Respondents with participant age Vs visual analog scale.

The 75 participants those were in the 23 - 33 age group 15 participants, 33 - 44 age group 17 participants and 45 - 56 age group 8 participants with VAS scoring was average 5. 23 - 33 age group 7 participants, 33 - 44 age group 14 participants and 45 - 56 age group 12 participants VAS scoring was average 7. 33 - 44 age group only 2 participants VAS scoring was average 9.

\begin{tabular}{|l|c|c|}
\hline Age of participants & Chi-Square & P-value \\
\cline { 2 - 3 } and visual analog scale & 117.82 & 0.436 \\
\hline
\end{tabular}

Table 6: Relationship between participant's age and visual analog scale.

This observed Chi-square value was 117.82 and P-value 0.436. So, there was no significant association between age of participants and influence on visual analog Scale of cervical spine. Therefore, employee who age group for 23 - 33, 34 - 44 and 45 - 56 did not differ significantly in relation to visual analog scale of cervical spine.

Respondents with working time Vs reading ability of the respondent (NDI)

\begin{tabular}{|l|c|c|c|}
\hline \multicolumn{4}{|c|}{ Reading ability of the respondent (NDI) } \\
\hline Working time & $\begin{array}{c}\text { Minimum } \\
\text { scoring } \\
\text { (1-2) }\end{array}$ & $\begin{array}{c}\text { Maximum } \\
\text { scoring } \\
\text { (3-4) }\end{array}$ & Total \\
\hline Group 1 (1-3) hours & 3 & 2 & 5 \\
\hline Group-2 (4-6) hours & 29 & 5 & 34 \\
\hline Group-3 (7-9) hours & 33 & 3 & 36 \\
\hline Total & 65 & 10 & 75 \\
\hline
\end{tabular}

Table 7: Respondents with working time Vs reading ability of the respondent (NDI).

The 75 participants those Were 5 participants was reading ability (minimum scoring 1 - 2 were 3 participants and maximum scoring 3 - 4 were 2 participants) with worked hours average 2 , were in the 34 participant's reading ability (minimum scoring 1-2 were 29 participant and maximum scoring 3 - 4 were 5 participants) with worked hours average 5 and 36 participants reading ability (minimum scoring 1 - 2 were 33 participant and maximum scoring 3 - 4 were 3 participants) with worked hours average 8 .

\begin{tabular}{|c|c|c|}
\hline Working time and reading ability & Chi-Square & P-value \\
\cline { 2 - 3 } of the respondent (NDI) & 32.86 & 0.048 \\
\hline
\end{tabular}

Table 8: Relationship between working time and reading ability of the Respondent (NDI).

This observed Chi-square value was 32.86 and P-value 0.048. So, the result was significant therefore, the more hours of reading the more chance to have neck pain among the study participants. 


\section{Discussion}

This study examined the factors influencing of neck pain among computer users. The study found that $78.67 \%$ suffered from computer users for neck pain. This result is comparable to Ranasinghe., et al. 2011 in Sri Lanka that (51\%) reported computer users in neck pain in last one year. This result also can be compared with a study in India by Das, 2010 which show that $89 \%$ computer users had been suffered from computer users in neck pain. In China a study was conducted by Cho., et al. 2012 where 69\% participants were suffered from computer users in neck pain. In Internet Journal of Pain, Symptom Control and Palliative Care 2005 Adedoyin., et al. stated that $73 \%$ reported about WRMSDs in Nigeria. This indicates that the percentage of WRMSDs of this study is almost similar to other studies in Asia and other countries.

Most frequent age ranges of participants (78.67\%) have suffered from neck pain in computer users in between 21 - 54 years followed by 75 participants. In Asian Journal of Medical Science 2010, it has been shown that 80 percent female and 67 percent male VDT workers of 26 - 35 years suffered discomfort feeling in India. Wahlstro, 2005 showed that $22 \%$ people in less than 35 years old were affected by WRMSDs, in between 35 - 45 years $30 \%$ people were suffered from WRMSDs and in more than 45 years old $48 \%$ people were suffered from WRMSDs. Here a verity in age range of affected group can be seen which may be because of sample size.

In this study the number of male participants was $62.7 \%$ ( $\mathrm{n}$ $=47)$ and female participants were $37.3 \%(n=28)$. In literature by Rahman and Atiya 2009, Majority $92 \%$ were male and female $8 \%$ female were affected by WRMSDs in Malaysia whereas this study shows that $71 \%$ male participants has greater prevalence of WRMSDs. In a research project that was published at 2004 by Adedoyin., et al. showed that $63.5 \%$ male and $36.5 \%$ female were suffered from WRMSDs in Nigeria. The statistic by Health and safety executive (2008) showed that male are more vulnerable to WRMSDs than female and the statistic is 2900 male in every 100000 males and 2400 female in every 100000 females. In Asian Journal of Medical Science 2010, it was Observed that 74 percent male and 84 percent female computer users suffered from discomfort feeling respectively in India. The other studies of Asia supports this study's findings that male are most commonly affected but the percentage differs may be the sample size is the cause as the most samples of this study were male.

Study found that pain intensity of the neck here statistical analysis maximum scoring $3-4$ were 67 participants with working hours 9. The association between working hours and pain intensity result was not significant. Personal care of the NDI analysis maximum scoring 3 - 4 were 71 participants with working hours 7 . The association between working hours and personal care result was not significant. Weights carrying of the respondent of NDI analysis maximum scoring 3 - 4 were 63 participants with working hours 6 . The association between working hours and weight carrying result was not significant. Reading ability of the respondent of NDI analysis minimum scoring 1 - 2 were 65 participants with working hours 5 . The association between working hours and reading result was significant. Headache of the respondent of NDI analysis minimum scoring 1 - 2 were 75 participants with working hours 7 . The association between working hours and headache result was not significant. Concentration of the respondent of NDI analysis minimum scoring 1 - 2 were 71 participants with working hours 7 . The association between working hours and concentration result was not significant. Work of the respondent of NDI analysis minimum scoring 1 - 2 were 74 participants with working hours 8 . The association between working hours and work result was not significant. Driving of the respondent of NDI analysis minimum scoring 1 - 2 were 74 participants with working hours 7 . The association between working hours and driving result was not significant Sleeping of the respondent of NDI analysis minimum scoring 1 - 2 were 72 participants with working hours 8 . The association between working hours and sleeping was not significant. Recreation of the respondent of NDI analysis minimum scoring 1-2 were 69 participants with working hours 7. The association between working hours and recreation was not significant. In this study Work of the respondent of NDI analysis range 2 and minimum scoring 1 and maximum scoring 3 whereas Ranasinghe., et al. 2011 showed $15.4 \%$ reported CANS causing disruption of normal activities in Sri Lanka. In this study 59\% participants approached physician for musculoskeletal discomfort. Ranasinghe., et al. 2011, found $1.1 \%$ seeking medical advice.

Study found that 75 participants those were in the 23 - 33 age group 15 participants, 33 - 44 age group 17 participants and 45 56 age group 8 participants with VAS scoring was average 5. 23-33 age group 7 participants, 33 - 44 age group 14 participants and 45 56 age group 12 participants VAS scoring was average 7. 33 - 44 age group only 2 participants VAS scoring was average 9. Ranasinghe., et al. 2011 conduct a study best productive years with peak frequency of symptoms occurring in the age range 33 - 55 with pain scale 7. So the result was not significant that indicate there with age and visual analog scale. 


\section{Conclusion}

Now a day's various types of computer related musculoskeletal disorders are increasing in Bangladesh due to increasing use of computer tremendously in all sectors to improve the quality of health care system as well as the efficiency of health workers and other workers. Work related musculoskeletal disorders have great impact causing severe long term pain, physical disability and give rise to huge costs for society. For the fulfillment of this study the investigator used a quantitative research model in the form of a prospective type survey. Conveniently 75 participants among the professional computer users were collected. The investigator used a questionnaire. Each participant was given a questionnaire to identify the work related neck pain among them and from the documents of the participants the researcher forms a data base for the total sample included in the study. From the data base, it was found that maximum participants had work related neck pain and males show greater prevalence. The participants who were between 1856 years were most commonly suffered from neck pain. The duration of job length and working hour per day have been played a vital role in developing neck pain. Professional computer users who had job experience more than 10 years and working hour more than 7 hours were most commonly suffered by neck pain. Practice of having rest between work influences the find out of neck pain. The participants who sometimes took break was mostly affected; this result sounds odd may be due to participants felt shy to give the right answer or something else. Most commonly affected body part was neck. Among the affected participants most had been off work. Most affected participants had no previous history of accident. The participants who were affected most of them attended by a physician but had an unknown diagnosis. Most of the participants received treatment among them only a few received physiotherapy along with medication and other treatment.

\section{Suggestions}

The author recommend that work demand should be reduced especially for the computer using bankers, since they are at higher risk of neck pain and construction of work station should be such that positioning the monitor forms an angle of between 15 to 45 degrees inferior to an imaginary horizontal line extended from the eye, whilst monitor should be 5 to $20 \mathrm{~cm}$ above the work table, generally the keyboard and mouse are supposed to be at around elbow height so that the forearm could be at 90 degrees with the wrist straight. Bankers should be educated on ergonomics, posture, taking breaks in between work and relaxation as this will ultimately improve job satisfaction and performance. The uses of software that will monitor time spent while working on computer and prompt the user to take a break when working for too long can also be employed. Work place modifications such as rotation policy among workers, alternating job works, flexible working hours should be employed.

\section{Acknowledgements}

The authors are so grateful to all participating health care professionals for their valuable time and kind help.

\section{Funding Support}

This article had academic research paper. There is no financial support.

\section{Conflict of interest}

None.

\section{Author's contributions}

Both authors made substantial contribution to the conception, design, analysis and interpretation of data.

\section{Bibliography}

1. Bernaards Claire M., et al. "The effectiveness of a work style intervention and a lifestyle physical activity intervention on the recovery from neck and upper limb symptoms in computer workers". Pain 132.1-2 (2007): 142-153.

2. Brandt, Lars Peter Andreas., et al. "Neck and shoulder symptoms and disorders among Danish computer workers". Scandinavian Journal of Work, Environment and Health (2004): 399409.

3. Cagnie Barbara., et al. "Individual and work related risk factors for neck pain among office workers: a cross sectional study". European Spine Journal 16.5 (2007): 679-686.

4. Chiu T T W., et al. "A study on the prevalence of and risk factors for neck pain among university academic staff in Hong Kong". Journal of Occupational Rehabilitation 12.2 (2002): 77-91.

5. Côté Pierre J., et al. "The factors associated with neck pain and its related disability in the Saskatchewan population". Spine 25.9 (2000): 1109-1117.

6. Côté Pierre., et al. "Management of neck pain and associated disorders: A clinical practice guideline from the Ontario Protocol for Traffic Injury Management (OPTIMa) Collaboration". European Spine Journal 25.7 (2016): 2000-2022. 
7. Cromie Jean E., et al. "Work-related musculoskeletal disorders and the culture of physical therapy". Physical Therapy 82.5 (2002): 459-472.

8. Juul-Kristensen Birgit., et al. "Computer users' risk factors for developing shoulder, elbow and back symptoms". Scandinavian Journal of Work, Environment and Health (2004): 390-398.

9. Korhonen Tellervo., et al. "Work related and individual predictors for incident neck pain among office employees working with video display units". Occupational and Environmental Medicine 60.7 (2003): 475-482.

10. Lau E M C., et al. "The prevalence of and risk factors for neck pain in Hong Kong Chinese". Journal of Public Health 18.4 (1996): 396-399.

11. Punnett Laura and Ulf Bergqvist. "National Institute for Working Life Ergonomic Expert Committee Document No 1Visual Display Unit Work and Upper Extremity Musculoskeletal Disorders A Review of Epidemiological Findings". 16 (1997).

12. Ranasinghe Priyanga., et al. "Work-related complaints of arm, neck and shoulder among computer office workers in an Asian country: prevalence and validation of a risk-factor questionnaire". BMC Musculoskeletal Disorders 12.1 (2011): 1-9.

13. Rempel D M., et al. "A randomized controlled trial evaluating the effects of two workstation interventions on upper body pain and incident musculoskeletal disorders among computer operators". Occupational and Environmental Medicine 63.5 (2006): 300-306.

14. Viikari-Juntura E., et al. "Longitudinal study on work related and individual risk factors affecting radiating neck pain". Occupational and Environmental Medicine 58.5 (2001): 345-352.

15. Winkel Jørgen and Rolf Westgaard. "Occupational and individual risk factors for shoulder-neck complaints: Part II-the scientific basis (literature review) for the guide". International Journal of Industrial Ergonomics 10.1-2 (1992): 85-104.

\section{Volume 5 Issue 7 July 2021}

(C) All rights are reserved by Dr Md Harun-Or-Rashid., et al. 